\title{
Effect of 1-Desamino-8-D-Arginine Vasopressin (DDAVP) on Vasopressin Release and Blood Pressure during Hemorrhage
}

\author{
KurakaZu SHIMIZU, AND AKIHIDE NAKAO* \\ Department of Internal Medicine, Tokyo Rosai (Occupational \\ Diseases and Injuries) Hospital, Tokyo 143, and *First Department \\ of Internal Medicine, Faculty of Medicine, University of Tokyo, \\ Tokyo 113, Japan
}

\begin{abstract}
Whether or not 1-desamino-8-D-arginine-vasopressin (DDAVP) reduces blood pressure or affects the release of arginine vasopressin (AVP) and renin is controversial, although evidence suggests AVP and renin are important in maintaining blood pressure during hemorrhage. We therefore investigated the effect of DDAVP on endogenous release of AVP and renin and on blood pressure during hemorrhage in dogs.

In the control group the hemorrhage was performed at a rate of $0.4 \mathrm{~m} l \cdot \mathrm{kg}^{-1} \cdot \mathrm{min}^{-1}$ for $40 \mathrm{~min}$ from the femoral artery. The plasma AVP concentration and renin activity (PRA) increased progressively in response to the hemorrhage, from $7.5 \pm 0.5$ to $40.3 \pm 7.3 \mathrm{pg} \cdot \mathrm{m} l^{-1}$, and from $11.8 \pm 1.5$ to $20.5 \pm 4.2$ $\mathrm{ng} \cdot \mathrm{m} l^{-1} \cdot \mathrm{h}^{-1}$, respectively, while blood pressure decreased slightly. In the DDAVP group, intravenous infusion of DDAVP $\left(2.5 \mathrm{ng} \cdot \mathrm{kg}^{-1} \cdot \mathrm{min}^{-1}\right.$ for $\left.40 \mathrm{~min}\right)$ and hemorrhage were simultaneously performed. The plasma DDAVP concentration increased progressively to $218 \pm 21.0 \mathrm{pg} \cdot \mathrm{m} l^{-1}$. There was no significant difference, however, between the control and DDAVP groups in the response of AVP, PRA and blood pressure. The results suggested that DDAVP may not affect the release of AVP and renin or blood pressure during hemorrhage.
\end{abstract}

Key words: Vasopressin, DDAVP, Vasopressin receptors, Renin, Blood pressure, Hemorrhage..

(Endocrinol Japon 39: 517-523, 1992)

THE PRESSOR action of arginine vasopressin $(A V P)$ is mediated by interaction with $V_{1}$ receptors in vascular smooth muscle cells, whereas its antidiuretic effect is due to its interaction with $\mathrm{V}_{2}$ receptors. It is well known that 1-desamino-8-Darginine-vasopressin (DDAVP) is a selective $\mathrm{V}_{2}$ agonist with essentially no pressor effect [1]. However, whether DDAVP has a depressor effect or not has been controversial. For example, MacGregor et al. [2] observed no change in blood pressure in humans who received DDAVP, but Bichet et al. [3] found that it depressed blood pressure and increased the release of renin. The

Received: February 26, 1992

Accepted: June 19, 1992

Correspondence to: Dr. Kurakazu SHIMIZU, Deputy Director, Tokyo Rosai Hospital, 4-13-21, South, Omori, Ota-ku, Tokyo 143, Japan. proposed mechanism of this depressor effect is an antagonistic effect on $V_{1}$ receptors [4], or interaction with extrarenal $\mathrm{V}_{2}$ receptors [3].

In most of these previous reports, however, plasma levels of DDAVP and AVP have not been measured, although there is evidence suggesting that circulating AVP may suppress its own secretion by a negative feedback $[5,6]$. Therefore, the possibility has not been completely ruled out that DDAVP may suppress endogenous AVP release and thus lower blood pressure.

There is considerable evidence that endogenous AVP plays an important role in the maintenance of blood pressure under such conditions as dehydration or hemorrhage [7-9]. Therefore, in this study, the effect of DDAVP on blood pressure as well as AVP and renin release has been investigated during hemorrhage. 


\section{Materials and Methods}

\section{Experimental protocols}

Experiments were performed in male mongrel dogs, weighing between $10-15 \mathrm{~kg}$. The animals were fasted overnight prior to the experiments, but were allowed free access to water. They were anesthetized with sodium pentobarbital (30 $\mathrm{mg} \cdot \mathrm{kg}^{-1}$, iv). The femoral artery and vein were cannulated and the urinary bladder was catheterized. After completing this surgery, the dogs were allowed to recover for at least $60 \mathrm{~min}$ before the first sampling of blood.

Experiments were performed on two groups. In the control group $(n=5)$, the dogs were bled from the femoral artery at a rate of $0.4 \mathrm{~m} l \cdot \mathrm{kg}^{-1} \cdot \mathrm{min}^{-1}$ for $40 \mathrm{~min}$. Blood samples were obtained from the arterial catheter used for bleeding before and at 5 , $10,20,30$, and $40 \mathrm{~min}$ after blood withdrawal had began. After stopping the hemorrhage at $40 \mathrm{~min}$, blood samples were taken at 50,60, 70, 80, and $100 \mathrm{~min}$ and, at each sampling, an equal volume of $7.0 \%$ dextran in $0.9 \%$ saline was injected intravenously. As a vehicle, $0.9 \%$ saline was infused intravenously at $0.1 \mathrm{~m} l \cdot \mathrm{kg}^{-1} \cdot \mathrm{min}^{-1}$ for $40 \mathrm{~min}$ during the hemorrhage.

In the experimental group (DDAVP group, $\mathrm{n}=5$ ), simultaneously with the hemorrhage, DDAVP (25 $\mathrm{ng} \cdot \mathrm{m} l^{-1}$ in $0.9 \% \mathrm{NaCl}$ ) was infused intravenously at a rate of $2.5 \mathrm{ng}(0.1 \mathrm{ml})$. $\mathrm{kg}^{-1} \cdot \min ^{-1}$ for $40 \mathrm{~min}$ and blood samples were obtained in the same way as in the control group. The blood pressure and heart rate were monitored.

Samples for the measurement of AVP, osmolality, $\mathrm{Na}, \mathrm{K}$, and $\mathrm{Cl}$ were collected in chilled, heparinized plastic syringes $(12 \mathrm{ml}$ for each sample). Samples for renin and aldosterone assay $(4 \mathrm{ml}$ each) were taken in plastic syringes, each containing $0.1 \mathrm{ml}$ of $4 \%$ EDTA in $0.9 \%$ saline. Blood was centrifuged at $4^{\circ} \mathrm{C}$ to separate plasma.

Assays

AVP and DDAVP were extracted from the plasma and assayed by radioimmunoassay using two kinds of vasopressin antisera as described previously [10]. In short, one antibody (A) reacts selectively with AVP and does not cross-react with DDAVP. The other antibody (B) completely
(100\%) cross-reacts with AVP and DDAVP. The DDAVP concentration was therefore estimated by subtracting the vasopressin concentration (AVP concentration) determined using antibody A from that (AVP + DDAVP concentration) determined with antibody $\mathrm{B}$. The sensitivity of the assay was 0.5 to $1.0 \mathrm{pg}$ per assay tube. The intra-assay and inter-assay coefficients of variation were $7.1 \%$ and $7.8 \%$, respectively.

Plasma renin activity (PRA) was measured by radioimmunoassay with a Gamma Cort PRA Kit (Travenol) and the aldosterone concentration was measured with an aldosterone RIA Kit II (Dainabot). Osmolality was measured with an Advanced Osmometer (Model 3L, Advanced Instruments Inc.). Sodium and potassium were measured with a Flame Photometer 343 (Instrumentation Laboratory de Puerto Rico, Ltd.). Creatinine was determined with an autonomic analyzer (Parallel, American Monitor Corporation).

\section{Statistics}

All data are expressed as the means \pm SEM. Comparisons of the control groups to the DDAVP groups were performed by means of two way analysis of variance (ANOVA). To make multiple comparisons with a control value, one way ANOVA followed by Dunnett's multiple comparison test was used.

\section{Results}

The changes in the plasma DDAVP concentration after DDAVP infusion are shown in Fig. 1. Plasma DDAVP increased rapidly to $216.3 \pm 21.0$ $\mathrm{pg} \cdot \mathrm{m} l^{-1}$ and, after the infusion was stopped, decreased in an exponential curve. The mean half-life of DDAVP based on the disappearance curve between 50 and $100 \mathrm{~min}$ was $34 \mathrm{~min}$.

The effects of hemorrhage on the plasma AVP concentration are shown in Fig. 2. Plasma AVP increased progressively, reaching its peak 10 to 20 min after the hemorrhage was stopped and then gradually decreased. There was no significant difference between the control and DDAVP groups in the plasma AVP levels.

The effects of hemorrhage on plasma renin activity are shown in Fig. 3. There was no significant difference between the control and 


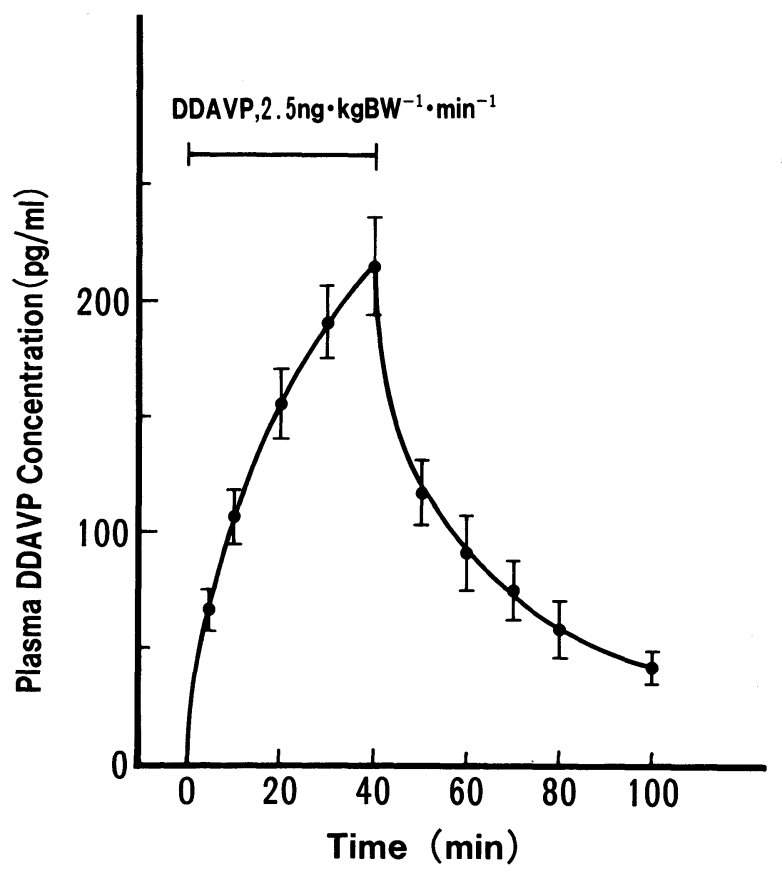

Fig. 1. The effect of intravenous infusion of DDAVP on plasma DDAVP concentration.

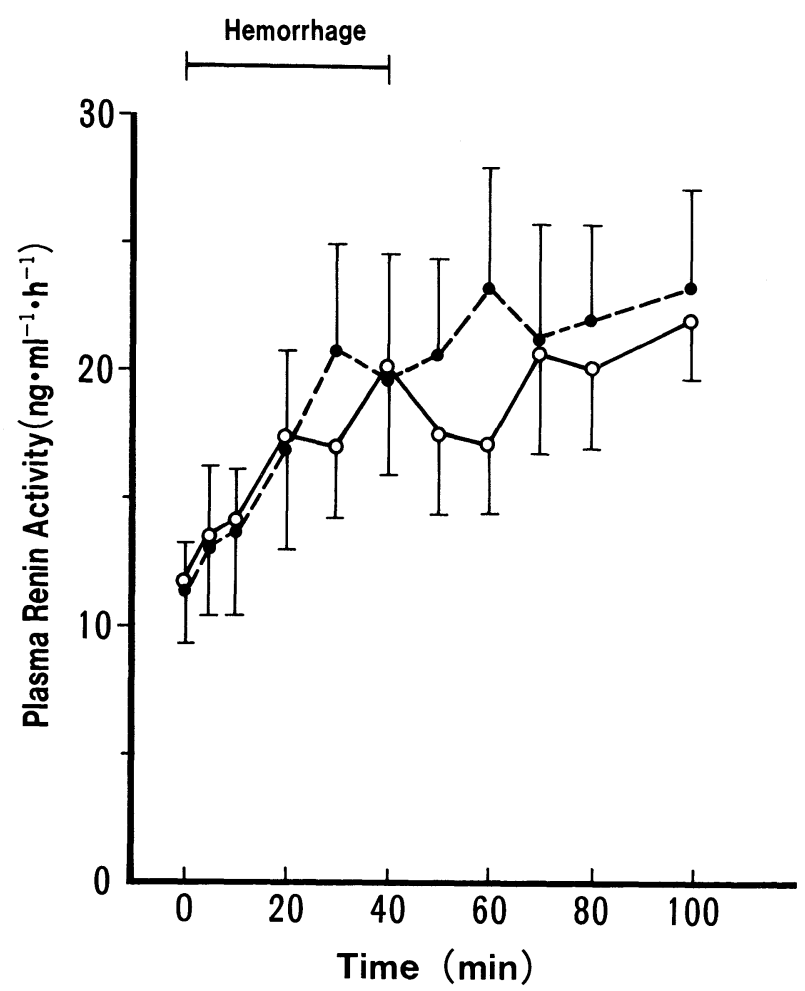

Fig. 3. The effect of hemorrhage on plasma renin activity in the control group (open circle) and the DDAVP group (solid circle).

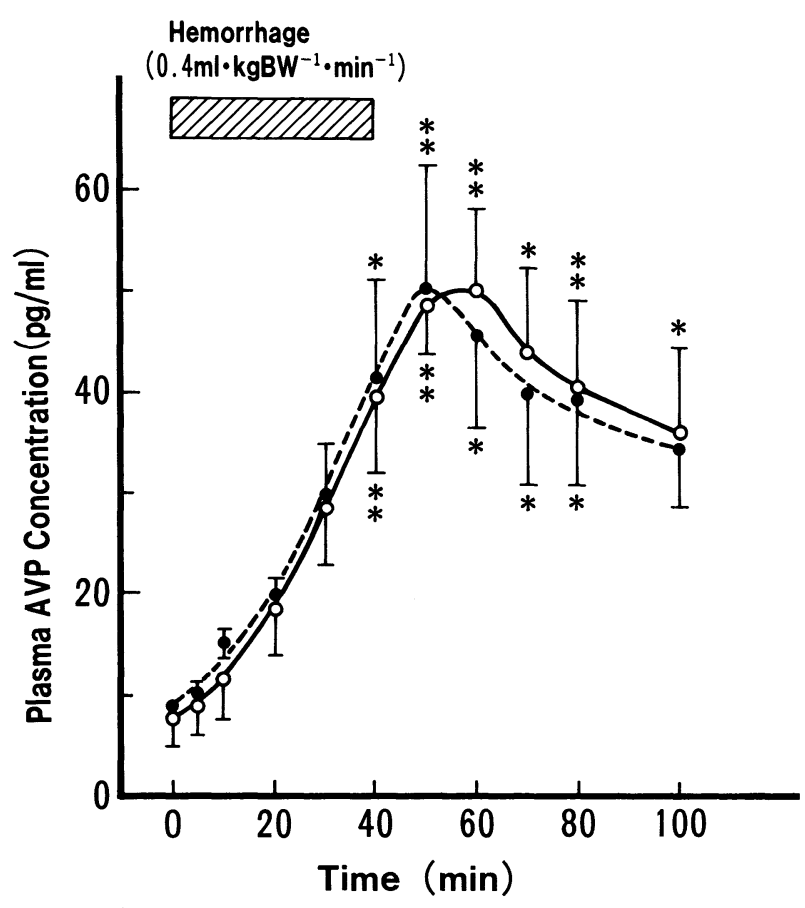

Fig. 2. The effect of hemorrhage alone (control group: open circle) and hemorrhage plus DDAVP infusion (DDAVP group: solid circle) on plasma AVP concentration. *, $P<0.05 ; * *, P<0.01$ vs. time 0 .

DDAVP groups in PRA. The plasma aldosterone concentration increased significantly from $131.8 \pm 22(0 \mathrm{~min})$ to $280 \pm 50.1(50 \mathrm{~min})$, and then decreased to $244.0 \pm 19.6 \mathrm{pg} \cdot \mathrm{m} l^{-1}(100 \mathrm{~min})$ in the control group. In the DDAVP group, a similar increase occurred, resulting in no significant difference between the two groups in the aldosterone response.

The plasma sodium, potassium, and creatinine concentration and osmolality did not change significantly in either group during these experiments.

The response of the mean arterial blood pressure $(\mathrm{MABP})$ and heart rate (HR) are shown in Fig. 4. MABP showed a slight, but at certain points statistically significant, reduction in the control group. Although the average MABP in the control group showed a larger reduction than in the DDAVP group, there was no statistically significant difference between the two groups in the changes in MABP and HR. MABP and HR before the start of the hemorrhage were 134.2 \pm 8.7 $\mathrm{mmHg}$ and $139.8 \pm 6.7$ beats $\cdot \mathrm{min}^{-1}$ in the control group and $136.7 \pm 4.3 \mathrm{mmHg}$ and $129.1 \pm 10.2$ beats. $\min ^{-1}$ in the DDAVP group with no significant difference between these two groups. 


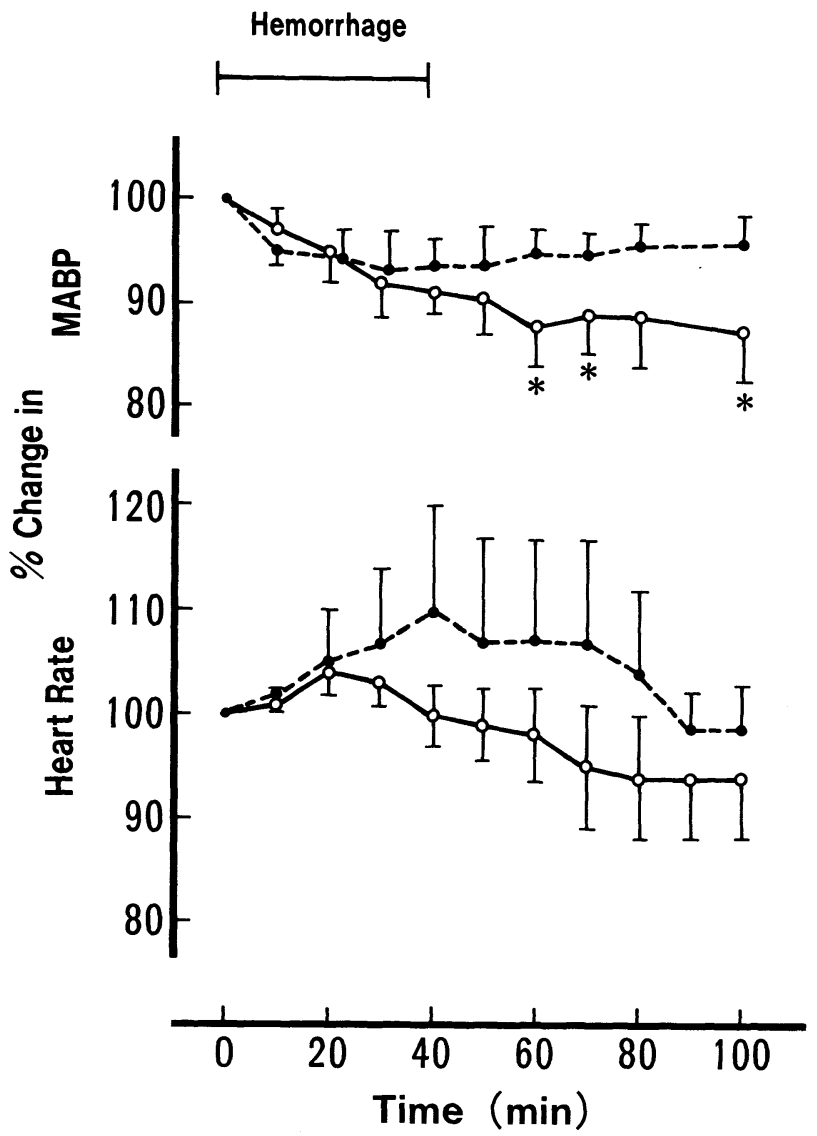

Fig. 4. The effect of hemorrhage on mean arterial blood pressure (MABP) and heart rate in the control group (open circle) and the DDAVP group (solid circle). The percentage change has been calculated from the pre-hemorrhage value. ${ }^{*}, P<0.05$ ws. time 0 .

\section{Discussion}

The present study demonstrated that peripherally administered DDAVP does not alter the release of AVP or blood pressure during hemorrhage.

As to AVP release, it has been suggested that AVP may suppress its own secretion by a negative feedback, since intracerebroventricular infusion of AVP reduces AVP secretion [5, 6]. Although AVP does not seem to cross the blood-brain-barrier (BBB) $[11,12]$, some areas of the brain, such as circumventricular organs, lack the BBB. The neurohypophysis has vasopressin binding sites [13, 14] and both AVP and DDAVP accumulate there [15]. Furthermore, peripherally administered AVP and DDAVP have the central effect of reducing the heart rate, and $\mathrm{V}_{2}$ receptors also seem to be involved in this effect $[16,17]$.
Similarly, peripherally administered angiotensin II has the central effect of stimulating AVP release, although angiotensin does not cross the BBB [18]. Therefore, the possibility exists that circulating vasopressin can alter its own release.

Brooks et al. [19] demonstrated that lysine vasopressin (LVP), a natural hormone in pigs, does not alter AVP release in dogs. However, LVP is about 10 times less potent in its antidiuretic action ( $\mathrm{V}_{2}$ receptor effect) than AVP in dogs [20], and therefore the possibility exists that $V_{2}$ receptors might be involved in such a feedback.

DDAVP has a similar affinity for $\mathrm{V}_{2}$ receptors to that of AVP [21], although DDAVP has an action of far longer duration than AVP because of its more delayed inactivation [22]. Therefore, in this study, the effect of DDAVP on AVP release was tested by measuring both peptides simultaneously. Although plasma DDAVP levels were found to be five times higher than AVP levels, DDAVP had no significant effect on AVP release. Since neither $V_{2}$ agonist DDAVP in this study nor LVP in the previous study [19], which has a potent $V_{1}$ effect in dogs [20], did have a significant effect on AVP release, it seems likely that circulating AVP may not provide a feedback to inhibit its own release.

As to the effect of DDAVP on blood pressure, many investigators have found that DDAVP has no effect on blood pressure under normal conditions in man [23-25] and animals [26]. However, its effect under hemorrhage conditions has not been studied. There is considerable evidence that AVP plays an important role in the maintenance of blood pressure, especially during hemorrhage or severe dehydration [7-9]. Therefore, it may be possible that DDAVP reduces blood pressure by suppressing AVP release and/or antanonizing the effect of AVP at vasopressor $V_{1}$ receptor sites. This possibility is also of clinical importance because DDAVP has been widely used for the treatment of not only patients with diabetes insipidus, but also hemophilia A and von Willebrand's disease [23-25].

Derkx et al. [4] demonstrated that intravenous infusion of large doses of DDAVP (400 $\mathrm{ng} \cdot \mathrm{kg}^{-1}$ over $10 \mathrm{~min}$ ) reduces blood pressure in man, especially in patients with autonomic nervous insufficiency. Although they did not measure the plasma AVP level, they concluded that DDAVP is a competitive antagonist of AVP on the $V_{1}$ receptors. 
A fall in blood pressure [27, 28] and a simultaneous rise in PRA [27], however, has been observed not only in normal subjects and dogs [28], but also in water-loaded subjects [8] and in patients with cranial diabetes insipidus [27]. This suggests that a mechanism other than the antagonism of endogenous AVP might exist. Furthermore, opposite to the effect on normal subjects, DDAVP was found not to cause blood pressure depression, renin release, or factor VIIIc release in patients with hereditary nephrogenic diabetes insipidus [3, 29], although not in all such patients [30]. Since factor VIIIc release seems to be mediated by interaction with extrarenal $\mathrm{V}_{2}$ receptors $[31,32]$ these results suggested that the depressor effect of DDAVP was related to the extrarenal $V_{2}$ receptors [29]. According to these previous studies, it is likely that the depressor action of DDAVP is mediated by its $V_{2}$ agonistic effect rather than its $V_{1}$ antagonistic effect.

In the present study, DDAVP showed no significant effect on blood pressure during the hemorrhage. The discrepancy between the previous and the present studies may be explained partly by the difference in the dosage of DDAVP used (300-400 $\mathrm{ng} \cdot \mathrm{kg}^{-1}$ versus $2.5 \mathrm{ng} \cdot \mathrm{kg}^{-1} \cdot \mathrm{min}^{-1}$, for $\left.40 \mathrm{~min}\right)$, because the qualitative relationship between plasma AVP and DDAVP levels may be critical for the DDAVP effect to occur, especially if extrarenal $V_{2}$ receptors are involved. It also seems likely that the pressor effect $\left(\mathrm{V}_{1}\right.$ effect) of increased endogenous AVP might have counteracted the depressor effect of DDAVP. To support this, it should be pointed out that in decapitated animals which cannot release AVP, a profound fall in arterial pressure is caused by another $\mathrm{V}_{2}$ agonist (VDAVP) [33]. It has also been shown that the extrarenal $V_{2}$ type activity of AVP is usually masked by its vasoconstrictor $\left(\mathrm{V}_{1}\right)$ type actions [34]. On the other hand, the inability of DDAVP to suppress blood pressure in this study may give some support to the theory that the depressor effect of DDAVP depends on its $\mathrm{V}_{2}$ agonistic effect, since selective $\mathrm{V}_{1}$ antagonists have generally suppressed blood pressure during hemorrhage or dehydration [7-9].

In this study, there occurred a progressive increase in PRA and the aldosterone concentration during hemorrhage, but DDAVP had no significant effect on these parameters. These results are in agreement with the previously reported findings indicating that acutely administered AVP suppresses basal PRA in vivo mainly by its vasoconstrictive activity, but not DDAVP [35, 36], which lacks this activity. Therefore, it seems likely that the renin release observed in some studies [3, $27,28]$ is closely related to a simultaneous fall in blood pressure.

In conclusion, the present study is the first one in which the effect of DDAVP on blood pressure and AVP release was tested during hemorrhage. It was demonstrated that DDAVP does not alter AVP release or blood pressure responses to hemorrhage when plasma DDAVP is raised to 200 $\mathrm{pg} \cdot \mathrm{m} l^{-1}$, with the DDAVP : AVP plasma ratio at 5:1. The inability to observe the depressor effect of DDAVP may be explained by the difference in the doses of DDAVP used and/or an increase in endogenous AVP release, but further studies will be necessary to define the exact mechanism of DDAVP effects.

\section{References}

1. Pliska V (1985) Pharmacology of deamino-darginine vasopressin. In: Czernichow P, Robinson AG (eds) Frontiers of Hormone Research. Diabetes Insipidus in Man. Basel, S. Karger, 13: 278-291.

2. MacGregor IR, Roberts EM, Prowse CV, Broomhead AF, Ozolins M, Litka P (1988) Fibrinolytic and haemostatic responses to desamino-D-arginine vasopressin (dDAVP) administered by intravenous and subcutaneous routes in healthy subjects. Thromb Haemostas 59: 34-39.

3. Bichet DG, Razi M, Lonergan M, Arthus M-F, Papukna V, Kortas C, Barjon J-N (1988) Hemodynamic and coagulation responses to 1 -
desamino[8-D-arginine]vasopressin in patients with congenital nephrogenic diabetes insipidus. $N$ Eng J Med 318: 881-887.

4. Derkx, FH, Man in't Veld AJ, Jones R, Reid JR, Schalekanp MADH (1983) DDAVP (1-desamino-8D-arginine vasopressin): an antagonist of the pressure action of endogenous vasopressin? $J$ Hypertension 1 (Suppl 2): 58-61.

5. Bhargava KP, Kulshrestha VK, Srivastava YP (1977) Central mechanism of vasopressin-induced changes in antidiuretic hormone release. $\mathrm{Br} \mathrm{J}$ Pharmacol 60: 77-81.

6. Wang BC, Share L, Crofton JT (1982) Central 
infusion of vasopressin decreased plasma vasopressin concentration in the dog. Am J Physiol 243: E365-E369.

7. Schwartz J, Reid IA (1981) Effect of vasopressin blockade on blood pressure regulation during hemorrhage in conscious dogs. Endocrinology 109: 1778-1780.

8. Padfield PL, Morton JJ (1985) Vasopressin and cardiovascular homeostasis. In: Baylis $\mathrm{PH}$, Padfield PL (eds) The Posterior Pituitary. Hormone Secretion in Health and Disease. Marcel Dekker, pp. 267-323.

9. Cowley AW Jr, Liard JF (1987) Cardiovascular actions of vasopressin. In: Gash DM and Boer GJ (eds) Vasopressin, Principles and Properties. Plenum Press, pp. 389-433.

10. Shimizu K, Nakao A, Nonaka T, Oka H (1984) Identification of vasopressin and determination of its corticomedullary levels in rat kidney tissue. Kidney Int 26: 785-790.

11. Stegner H, Artman HG, Leake RD, Fisher DA (1983) Does DDAVP (1-desamino-8-D-arginine vasopressin) cross the blood-CSF barrier? Neuroendocrinology 37: 262-265.

12. Ang VT, Jenkins JS (1983) Blood-cerebrospinal fluid barrier to arginine-vasopressin, desmopressin and desglycinamide arginine-vasopressin in the dog. J Endocrinol 93: 319-325.

13. Bunn SJ, Hanley MR, Wilkin GP (1986) Autoradiographic localization of peripheral benzodiazepine, dihydroalprenolol and arginine vasopressin binding sites in the pituitaries of control, stalk transected and Brattleboro rat. Neuroendocrinology 44: 76-83.

14. Van Leeuwen FW (1987) Vasopressin receptors in the brain and pituitary. In: Gash DM and Boer GJ (eds) Vasopressin, Principles and Properties. Plenum Press, pp. 477-496.

15. Janaky T, Laczi F, Laszlo FA (1982) Biological half-lives and organ distribution of tritiated 8lysine-vasopressin and 1-desamino-8-D-arginine vasopressin in Brattleboro rats. Ann NY Acad Sci 394: 116-227.

16. Patel KP, Schmid PG (1988) Role of median preoptic area in vasopressin-mediated bradycardia. Am J Physiol 254: H1172-178.

17. Imai Y, Nolan PL, Johnston CI (1983) Restoration of suppressed baroreflex sensitivity in rats with hereditary diabetes insipidus (Brattleboro rats) by arginine-vasopressin and DDAVP. Circulation Res 53: 140-149.

18. Shimizu K, Share L, Claybaugh JR (1973) Potentiation by angiotensin II of the vasopressin response to an increasing plasma osmolality. Endocrinology 93: 42-50.

19. Brooks DP, Share L, Crofton J, Matsui K, Rockhold RW (1984) Effect of vertebral, carotid and intravenous infusions of lysine vasopressin on plasma vasopressin and cardiovascular function. Neuroendocrinology 39: 350-355.

20. Van Dyke HB, Engel SL, Adamsons K (1956) Comparisons of pharmacological effects of lysine and arginine vasopressin. Proc Soc Exp Biol Med 91: 484-488.

21. Butlen D, Guillon G, Rajerison RM, Jard S (1978) Structural requirements for activation of vasopressin-sensitive adenylate cyclase, hormone binding and antidiuretic action: effects of highly potent analogue and competitive inhibitors. Mol Pharmacol 14: 1006-1017.

22. Shimizu K, Hoshino M, Kumagaya J, Oda J (1980) Mechanisms of the prolonged antidiuretic action of DDAVP and its metabolic features. In: Yoshida S, Share L and Yagi K (eds) Antidiuretic Hormone, Tokyo, Japan Sci Soc Press, and Baltimore, University Park Press. pp 271-284.

23. Warrier AZ, Lusher JM (1983) DDAVP: a useful alternative to blood components in moderate hemophilia A and von Willebrand disease. J Pediatr 102: 228-233.

24. Andersson KE, Arner B (1972) Effect of DDAVP, a synthetic analogue of vasopressin, in patients with cranial diabetes insipidus. Acta Med Scand 192: 21-27.

25. Richardson DW, Robinson AG (1985) Desmopressin. Ann Int Med 103: 228-239.

26. Stegner H, Artman HG, Leake RD, Fisher DA (1984) DDAVP clearance rate. Acta Endocrinol 107: 202-206.

27. Williams TDM, Lightman SL, Leadbeater MJ (1986) Hormonal and cardiovascular responses to dDAVP in man. Clin Endocrinol 24: 89-96.

28. Liard JF (1988) Characteristics of acute hemodynamic effects of antidiuretic agonists in conscious dogs. J Cardiovasc Pharmacol 11: 174-180.

29. Bichet DG, Razi M, Arthus MF, Lonergan M, Tittley P, Smiley RK, Rock G, Hirsch DJ (1985) Epinephrine and dDAVP administration in patients with congenital nephrogenic diabetes insipidus. Evidence for a pre-cyclic AMP $\mathrm{V}_{2}$ receptor defective mechanism. Kidney Int 36: 859-866.

30. Brenner B, Seligsohn U, Hochberg Z (1988) Normal response of factor VIII and von Willebrand factor to 1-desamino-8-D-arginine vasopres$\sin$ in nephrogenic diabetes insipidus. J Clin Endocrinol Metab 67: 191-193.

31. Mannucci PM, Aberg M, Nilsson IM, Robertson B (1975) Mechanism of plasminogen activator and factor VIII increase after vasoactive drugs. $\mathrm{Br} . \mathrm{J}$ Haematol 30: 81-93.

32. Mannucci PM, Canciani MTRL, Donovan BS (1981) Response of factor VIII/von Willebrand factor to dDAVP in healthy subjects and patients with haemophilia A and von Willebrand's disease. 
Br J Haematol 47: 283-293.

33. Liard JF (1989) Peripheral vasodilalation induced by a vasopressin analogue with selective $\mathrm{V}_{2^{-}}$ agonism in dogs. Am J Physiol 256: H1621-1626.

34. Schwartz J, Liard JF, Ott C, Cowley AW Jr (1985) Hemodynamic effects of neurohypophyseal peptides with antidiuretic activity in dogs. Am J Physiol 249: H1001-1008.
35. Johnson MD, Kinter LB, Beeuwkes III R (1979) Effects of AVP and DDAVP on plasma renin activity and electrolyte excretion in conscious dogs. Am J Physiol 236: F66-70.

36. Reid IA (1985) Inhibition of renin secretion by vasopressin: mechanisms and physiological role. In: Schrier RW (ed) Vasopressin, Raven Press, NY, pp. 21-28. 